\title{
ECONOMIA E TRÁFICO DE AFRICANOS ESCRAVIZADOS NA PARAÍBA DA PRIMEIRA METADE DO SÉCULO XIX
}

\author{
Matheus Silveira Guimarães*
}

\begin{abstract}
RESUMO: Este artigo tem como objetivo apresentar o resultado de pesquisa acerca do comércio de africanos/as escravizados/as para a capitania/província da Paraíba na primeira metade do século XIX. Os estudos sobre escravidão no Brasil têm avançado significativamente, entretanto, algumas lacunas ainda precisam ser preenchidas. Uma delas consiste em abordar os portos não centrais para o comércio atlântico de escravizados/as, como era o exemplo da Paraíba. Outra lacuna refere-se ao comércio interno existente antes de 1850 , período que marca o fim do tráfico atlântico e intensifica o comércio intraprovincial.
\end{abstract}

PALAVRAS-CHAVE: Escravos; Africanos; Tráfico; Paraíba.

\section{Economy and africans slave trade in Paraíba of nineteenth first half}

ABSTRACT: The aim of this article is to present the result of research about the trade of africans slaves brought to capitance/province of Paraíba, in the first half of XIXth century. The studies about slavery in Brazil has been advanced, however, some gaps still needs to be filled. One is to approach the non-central ports of atlantic slaves trade, for example of Paraíba. Other gap is the internal slave trade existing before 1850, period that atlantic slave trade finished and internal trade intensifies.

KEYWORDS: Slaves; Africans; Traffic; Paraíba.

\section{Economía y comercio de africanos esclavizados en Paraíba de primera mitad del siglo XIX}

RESUMEN: Este artículo tiene como objetivo presentar el resultado de pesquisa acierca del comercio de africanos esclavos para la capitanía/provincia de Paraíba en primera mitad del siglo XIX. Los estudios acierca de esclavitud en Brasil tienen avanzado, sin embargo, algunas brechas aún necesitan ser llenada. Una de ellas consiste enfocar los puertos no centrales en comercio atlántico de esclavos, como ejemplo de Paraíba. Otra brecha se refiere al comercio interno existente antes de 1850, período que el tráfico atlántico se termina y se intensifica el comercio interprovincial.

PALABRAS CLAVE: Esclavos; Africanos; Trafico; Paraíba.

\footnotetext{
* Mestre em História pela Universidade Federal da Paraíba. Associado à Associação Nacional de História (ANPUH) e à Sociedade Brasileira de Estudos do Oitocentos (SEO). Atualmente, é professor substituto na Universidade Estadual da Paraíba. Contato: Rua Baraúnas, 351 - Universitário, CEP: 58429-500, Campina Grande - PB, Brasil. E-mail: guimaraesmatheuss@gmail.com
} 


\section{Introdução}

O comércio atlântico de pessoas foi uma das práticas mais importantes da modernidade, tendo impacto direto sobre três continentes: Europa, África e América. Não podemos pensar a formação desses continentes desde o século XVI sem destacarmos o papel do comércio de escravizados. Em particular, no caso do Brasil, essa situação torna-se ainda mais marcante. Por cerca de três séculos o Brasil esteve conectado ao mundo atlântico por intermédio dessa atividade econômica.

Exatamente por sua importância, esse fenômeno tem sido cada vez mais estudado e muitos de seus detalhes estão vindo à tona, apesar de termos muito ainda por avançar. No Brasil, destacam-se pesquisas sobre os principais portos de embarques - Rio de Janeiro, Salvador e Recife. Entretanto, surge uma questão: tendo em vista que a escravidão foi uma instituição que permeou todo o território brasileiro e que a presença africana era comum em todos os lugares do Brasil, como se davam as relações comerciais entre as rotas de escravos e as capitanias/províncias de menor representação econômica?

No século XIX, o comércio de africanos aumentou em sua intensidade, tornando-se ilegal em 1831 - mas ainda assim, manteve-se com altas taxas de importação- e foi definitivamente suspenso em 1850. A primeira metade desse século, assim, teve fundamental importância para o tráfico e esta atividade interferiu diretamente na formação política e econômica do império no referido período.

Este trabalho tem como objetivo lançar luz sobre essa questão, destacando o caso particular da capitania/província da Paraíba. Nunca aparecendo como grande porto de entrada de africanos, tal capitania/província, contudo, importava escravos. Como isso se dava? Quais as rotas desse comércio que conectavam a Paraíba ao mundo atlântico? Quais eram suas demandas econômicas?

\section{Economia da Paraíba na primeira metade do século XIX}

A primeira metade do século XIX foi, para a capitania/província da Paraíba, marcada por altos e baixos. Logo após a reconquista de sua autonomia, houve, por exemplo, um esforço em criar condições institucionais de gerência financeira (como foi o caso da Junta Real da Fazenda criada em 1809). Para além disso, a produção do ouro branco (algodão) 
expandiu-se significativamente, promovendo o enriquecimento de alguns setores das elites da capitania/província. Entretanto, os anos imediatamente posteriores à independência do Brasil não representaram grande opulência e houve queda nas taxas de exportação. Apenas ao final da década de 1830 que a Paraíba estabilizou-se economicamente. Esses fatores interferiram diretamente na forma como esta se inseriu no mundo atlântico.

Durante 44 anos, Pernambuco ficou responsável pela administração política e econômica de sua vizinha, tornando o cargo de governador-mor da Paraíba apenas como honorífico. Por toda essa época, foram constantes as reclamações de setores da elite econômica da Paraíba frente a essa situação ${ }^{1}$. Após muitas cartas da Câmara da Parahyba ${ }^{2}$ ao Conselho Ultramarino reivindicando a retomada da autonomia, a Rainha D. Maria I resolveu acabar com a subordinação oficial da Paraíba a Pernambuco, nomeando Fernando Delgado Freire de Castilho para o cargo de governador daquela capitania. Ele ficaria encarregado de traçar com detalhes a situação e auxiliar na tomada de decisão sobre o assunto (PINTO, 1977, Vol. I, p. 180).

O relatório de Fernando Castilho é, talvez, uma das descrições mais completas da Paraíba no período colonial. O primeiro destaque dado pelo governador foi sobre a situação dos comerciantes da capitania. De acordo com ele, estes eram poucos e estavam submetidos a uma situação de pobreza. A principal razão para isso era a subordinação a Pernambuco que havia reduzido a capacidade de desenvolvimento da Paraíba. A alternativa apresentada para solucionar o problema seria conceder a autonomia, reconquistada oficialmente em 1799 (AHU_CU_014, Cx. 34, D. 2473, 1799). Mesmo conseguindo oficialmente se desenlaçar de Pernambuco, a Paraíba permaneceu economicamente sob a sombra daquela. O processo de reconstrução da demorou para se efetivar, como ficou visível com a dificuldade na criação da Junta Real da Fazenda, que só se tornou possível dez anos depois da desanexação.

Apesar de ter sido desanexada, as relações comerciais da Paraíba continuaram dependentes de sua vizinha, como já afirmamos. Essa situação permaneceu porque Recife possuía um porto mais ativo, sendo central na economia da região das capitanias do Norte. Além do mais, parte dos produtores e comerciantes da Paraíba estavam conectados aos pernambucanos por intermédio de empréstimos.

A historiografia vinculada ao Instituto Histórico e Geográfico Paraibano (IHGP) tende a aceitar o período inicial do século XIX como desastroso para a Paraíba. Seu objetivo era tornar a experiência da subordinação mais impactante ${ }^{3}$. Entretanto, não acreditamos ter sido esse período extremamente negativo. Apesar da subordinação econômica a Recife, a Paraíba 
continuou relacionando-se com portos vizinhos a exemplo de Aracati, Mossoró e Goiana, o que provavelmente permitiu que a capitania continuasse com vivacidade em sua economia (PAIVA, 2009).

Além disso, o quadro geral era favorável no início do Oitocentos. O final do século XVIII permitiu um crescimento econômico do Brasil, que também se fez presente na capitania da Paraíba. Autores como Caio Prado Júnior (2006) denominaram esse período como "Renascimento Agrícola". Vários fatores permitiram essa retomada da produção no Brasil. O primeiro deles diz respeito à revolução do Haiti. Este país era um dos principais concorrentes do Brasil na produção de açúcar. Os conflitos internos e externos do processo revolucionário fizeram com que a produção haitiana entrasse em declínio, deixando espaço no mercado que passou a ser ocupado pelo Brasil (MARQUESE;TOMICH, 2009)

Nesse período, por todo o país, expandiram-se as unidades produtivas do açúcar. A Paraíba apresentava bons números desde o final do século XVIII. Essa característica foi percebida por Fernando Delgado de Castilho, que identificou a fertilidade e qualidade da terra e do açúcar da região, apontando para a grande potencialidade dessa produção, desde que incentivada. Tal potencialidade era possível graças às boas taxas pluviométricas e boas condições das várzeas dos rios como o Paraíba e o Mamanguape.

Nesse período, a capitania possuía cerca de 32 engenhos(NASCIMENTO FILHO, 2006, p. 31). Se utilizarmos os dados apresentados pelos governadores em relação à produção de açúcar, chegaremos aos seguintes números médios:

Quadro 1 - Média da produção de açúcar na Paraíba por engenho (1798-1805)

\begin{tabular}{|l|l|l|l|l|l|l|l|}
\hline Anos & $\mathbf{1 7 9 8}$ & $\mathbf{1 7 9 9}$ & $\mathbf{1 8 0 0}$ & $\mathbf{1 8 0 1}$ & $\mathbf{1 8 0 2}$ & $\mathbf{1 8 0 4}$ & $\mathbf{1 8 0 5}$ \\
\hline Produção em arroba & 37.376 & 27.576 & 30.828 & 14.708 & 9.520 & 9.252 & 14.564 \\
\hline Média por engenho & 1.168 & 861,75 & 963,37 & 459,62 & 297,50 & 289,12 & 455,12 \\
\hline
\end{tabular}

Fontes: AHU_CU_014, Cx. 34, D. 2473, 1798; AHU_CU_014, Cx. 34, D. 2490, 1799; AHU_CU_014, Cx. 36, D. 2575, 1800; AHU_CU_014, Cx. 37, D. 2673, 1801; AHU_CU_014, Cx. 39, D. 2744, 1802; AHU_CU_014, Cx. 40, D. 2807, 1803; AHU_CU_014, Cx. 42, D. 2989, 1804; AHU_CU_014, Cx. 45, D. 3200, 1805; AHU_CU_014, Cx. 47, D. 3314, $1806 .{ }^{4}$

Diante desse quadro, tivemos uma pequena oscilação nos últimos anos do século XVIII, mas que não comprometeu gravemente o quadro geral da produção. Os dados de 1801,1802 e 1804 demonstram forte queda na produção geral e média de açúcar. Em 1805, 
indicaram uma possível retomada no crescimento. Esse período, ainda que curto, demonstra certa instabilidade na produção. Duas possíveis explicações para isso consistem, por um lado, em uma readaptação à condição de autonomia e, por outro, devido às variações nos preços do açúcar vividas nos anos inicias do século XIX.

Outro fator para se pensar a retomada da produção no Brasil foi a revolução industrial. Esta foi protagonizada, sobretudo, pelo setor têxtil. A industrialização aumentou a demanda por algodão, que já era produzido no Brasil e tornou-se um dos principais produtos da região. O boom algodoeiro foi tão intenso que chegou a comprometer a produção de açúcar, a principal mercadoria até então. Muitos dos produtores que estavam envolvidos com essa atividade passaram a se voltar para o algodão graças ao crescimento das exportações. Apesar do crescimento produtivo e da riqueza que passou a gerar, a atividade algodoeira era muito rudimentar na Paraíba e em todo o Brasil. (AHU_CU_014, Cx. 34, D. 2473, 1799; LUNA; KLEIN, 2010). Esse desenvolvimento algodoeiro na Paraíba, inclusive, chegou a fortalecer uma elite econômica que, diante de um cenário de pressão econômica sofrido com a transferência da Corte para o Rio de Janeiro, decidiu enfrentar o centro político no movimento de $1817^{5}$.

Apesar de ter sido protagonizada pelas culturas de cana de açúcar e algodão, a melhoria econômica da Paraíba no início do século XIX também se deu graças a outras atividades, dentre as quais, destacaremos duas: a pecuária e a extração de madeiras. A criação de gado manteve-se relativamente estável, alterando-se apenas em períodos de secas. De acordo com os relatórios apresentados pelos governadores da capitania entre 1798 e 1805, os anos de 1798 e 1799 tiveram como produção 8.646 e 6.923 cabeças, respectivamente. Tais números quase dobraram em 1800 e mantiveram-se em 1801 no mesmo nível (13.094 e 13.224 cabeças $)^{6}$. Os anos de 1802 e 1804 apresentaram forte queda, devido à seca, recuperando-se no ano seguinte. Vale ressaltar que muitos dos senhores de engenhos situados no litoral tinham fazendas de gado no sertão, o que permitia a eles diversificar maneiras de aumentarem suas riquezas.

As secas aconteciam constantemente na Paraíba e também serviram como estratégia dos proprietários da capitania para pedirem isenção das taxas de importação de africanos. Em 1806, por exemplo, os senhores de engenho e fazendeiros enviaram ao Conselho Ultramarino um pedido de isenção dos direitos sobre a importação de escravos, pois a seca do ano anterior havia deixado "em total ruína os habitantes destes sertões, pela mortandade dos gados, que 
jamais podião existir pela falta de pastos, e os engenhos ficarão igualmente destruídos na sua escravatura" (AHU_CU_014, Cx. 47, D. 3345, 1806).

Outra atividade desenvolvida era a extração de madeiras. Boa parte do relato de Fernando Delgado Castilho destaca "a qualidade e extensão das matas" e os tipos de madeira para construção naval e outros fins como móveis, tintas etc. (PINTO, 1977, Vol. I, p. 182), concluindo que "as matas abundam em madeiras para a Marinha Real, para moveis, e imbutidos, e para os edifícios dos prédios rústicos e urbanos" (AHU_CU_014, Cx. 34, D. $2473,1799)$. Muito atento a essa questão, o governador observara que essa atividade não era tão aproveitada até então, pois era realizada a um alto custo e acabava rivalizando com algumas plantações (AHU_CU_014, Cx. 34, D. 2471, 1798).

Por todas essas condições, os saldos da capitania da Paraíba entre os anos de 1798 e 1805 foram positivos em quase todos os anos. As exportações foram, em geral, maiores do que as importações, permitindo que se arrecadasse mais. Como podemos observar a seguir:

Gráfico 1 - Exportação e importação da Capitania da Paraíba (1798-1805)

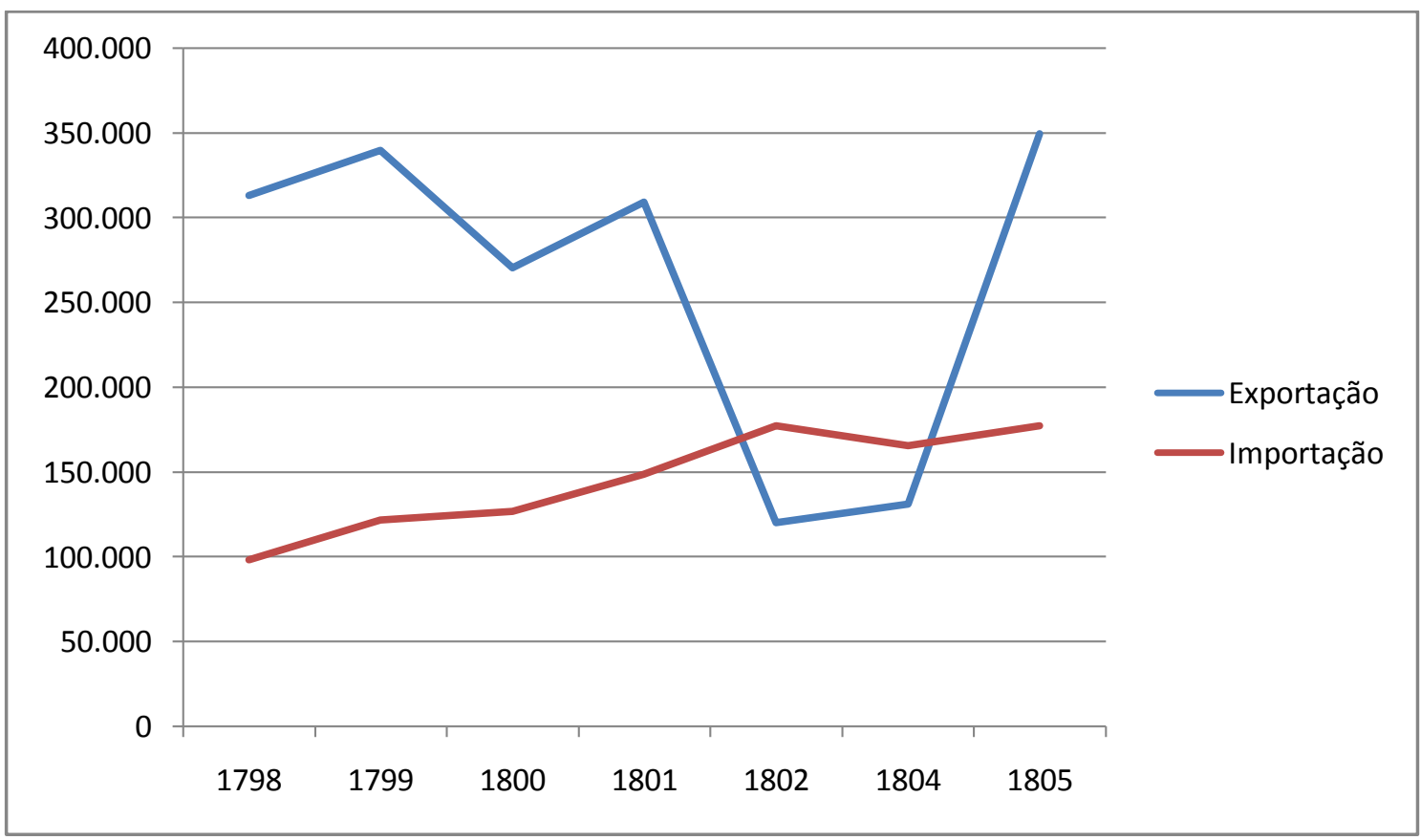

Fontes: AHU_CU_014, Cx. 34, D. 2473, 1799; AHU_CU_014, Cx. 34, D. 2490, 1799; AHU_CU_014, Cx. 36, D. 2575, 1800; AHU_CU_014, Cx. 37, D. 2673, 1801; AHU_CU_014, Cx. 39, D. 2744, 1802; AHU_CU_014, Cx. 40, D. 2807, 1803; AHU_CU_014, Cx. 42, D. 2989, 1804; AHU_CU_014, Cx. 45, D. 3200, 1805; AHU_CU_014, Cx. 47, D. 3314, $1806^{7}$.

Durante os últimos anos do século XVIII, as exportações da Paraíba apresentaram bons números. Caindo entre os anos de 1801 e 1802, as vendas para o exterior retomam no 
ano seguinte, crescendo consideravelmente em 1805. Apesar dessas oscilações, em quase todo o recorte, as exportações foram superiores às importações, demonstrando uma constante superavitária. Dentre os exportados, estavam o açúcar, produtos derivados da pecuária e algodão. Quando se tratava de importações, a capitania focava em panos de linho, chitas bretanhas e farinha do reino.

Porém, a década seguinte levou a uma queda desses números. A conjuntura do Brasil não era favorável. Entre os anos de 1816 e 1822, a balança comercial tornou-se deficitária. Os preços do algodão e açúcar que - como vimos - eram fundamentais à economia brasileira tornaram-se irregulares no mercado. O quadro ficou ainda mais comprometido no período posterior à independência. Os gastos referentes ao processo de independência, seguidos pelas indenizações pagas a Portugal $^{8}$, dificultaram a conjuntura. Para completar a situação, os acordos internacionais bilaterais assinados deixaram o Brasil em situação de fragilidade, pois este precisava do reconhecimento internacional e, para isso, acabou cedendo em muitos aspectos, iniciando um período de imobilidade no cenário internacional (CERVO; BUENO, 2008). Entre 1825 e 1828, o Império brasileiro envolveu-se na Guerra da Cisplatina que aprofundou ainda mais a crise e desgastou a imagem de d. Pedro I.

Mesmo com tais dificuldades, a economia da Paraíba apresentou importantes características em mudança. A primeira delas diz respeito a um aumento do número de comerciantes que passaram a não privilegiar o porto de Recife. Alguns deles eram ingleses que, com a abertura dos portos, se instalaram no Brasil. Na Paraíba, dois tiveram importante destaque. Mac Klakan chegou por volta do ano de 1814. Após se estabelecer nessa capitania, criou rotas comerciais que rivalizavam com as de Recife. Nas palavras de Horácio de Almeida (1978, Vol. II, p. 89), “O inglês mandava vir de sua nação embarcações para escoamento da safra da Paraíba, não só de açúcar, como de algodão, couro, fumo, madeira, etc. Os navios subiam o Paraíba e atracavam no canal do Sanhauá, defronte ao Varadouro". De acordo com o mesmo autor, as rivalidades comerciais chegaram até a Corte devido às reclamações dos comerciantes de Recife requerendo a proibição de Mac Klakan de exercer suas atividades.

O segundo comerciante inglês de destaque foi Carlos Holmes que iniciou suas atividades econômicas na Paraíba no período da Independência ao negociar armas e paubrasil. Estabeleceu-se na província e construiu laços de sociabilidades não só com as elites locais, bem como com a população livre pobre e escravizada. Seu nome foi um dos mais frequentes nos registro de batismo da Freguesia de Nossa Senhora das Neves entre os anos de 
1833 e 1860. Os Livros de Notas também são fontes em que o nome de Holmes aparece várias vezes movimentando o comércio local ao vender, comprar e trocar bens e imóveis ${ }^{9}$.

Nesse período, há também a consolidação do mercado do algodão na Paraíba. As fontes são poucas para quantificar isso, porém na historiografia conseguimos identificar alguns dados. De acordo com Celso Mariz (1978, p. 16) e Irineu Pinto (1977, Vol. I, p. 236, 245), em 1813, o algodão apresentava um rendimento de 10 contos de réis (10:000\$000). Em 1815 , este número subiu para 25:668\$000. No ano seguinte, chegou a 45:655\$000 do total da renda da capitania. Ou seja, em três anos os rendimentos do algodão mais do que quadruplicaram. Foi nesse contexto que se consolidou a elite econômica algodoeira que compôs o movimento de 1817 , como destacamos.

A partir da década de 1830, identificamos certa estabilização da economia da Paraíba. Vejamos a tabela a seguir.

Tabela 1 - Receitas e despesas da Província da Paraíba (1837 - 1850)

\begin{tabular}{llll}
\hline Ano & Receitas & Despesas & Saldo \\
\hline $\mathbf{1 8 3 7}$ & $96: 892 \$ 000$ & $86: 146 \$ 000$ & $+10: 746 \$ 000$ \\
$\mathbf{1 8 3 8}$ & ----- & ---- & $+18: 952 \$ 892$ \\
$\mathbf{1 8 3 9}$ & $135: 995 \$ 132$ & $112: 188 \$ 298$ & $+23: 806 \$ 936$ \\
$\mathbf{1 8 4 1}$ & $146: 776 \$ 251$ & $144: 326 \$ 612$ & $+2: 449 \$ 639$ \\
$\mathbf{1 8 4 2}$ & $157: 660 \$ 980$ & $116: 670 \$ 375$ & $+40: 990 \$ 605$ \\
$\mathbf{1 8 4 3}$ & $143: 956 \$ 207$ & $121: 162 \$ 623$ & $+22: 793 \$ 584$ \\
$\mathbf{1 8 4 4}$ & $114: 912 \$ 585$ & $94: 016 \$ 974$ & $+20: 895 \$ 611$ \\
$\mathbf{1 8 4 5}$ & $158: 400 \$ 294$ & $105: 881 \$ 937$ & $+52: 518 \$ 357$ \\
$\mathbf{1 8 4 6}$ & $177: 143 \$ 209$ & $162: 699 \$ 792$ & $+14: 443 \$ 792$ \\
$\mathbf{1 8 4 7}$ & $157: 972 \$ 593$ & $130: 598 \$ 721$ & $+27: 373 \$ 887$ \\
$\mathbf{1 8 4 8}$ & $195: 884 \$ 304$ & $146: 843 \$ 706$ & $+49: 035 \$ 798$ \\
$\mathbf{1 8 4 9}$ & $236: 188 \$ 068$ & $173: 077 \$ 700$ & $+63: 110 \$ 368$ \\
$\mathbf{1 8 5 0}$ & $121: 722 \$ 515$ & $166: 970 \$ 936$ & $+45: 284 \$ 421$ \\
\hline
\end{tabular}

Fontes: Relatórios de Presidente de Província da Paraíba de 1837 a 1850. 
Esses números demonstram uma constante positiva nos saldos da província. Apesar das oscilações, a Paraíba conseguiu até 1850 fechar as contas com certa tranquilidade. O triênio 1837/38/39, por exemplo, foi de crescimento, tendo grande queda no ano de 1841 . Entre 1843-45, novamente os saldos voltam a se apresentar em crescimento após a queda ocorrida entre 1842-43. O mesmo ocorre entre 1845-46, em que há uma grande queda nos saldos, apesar de se manterem positivos. Contudo, voltam a crescer nos anos seguintes e ficam relativamente estabilizados no final da primeira metade do século.

Em linhas gerais, podemos afirmar que a situação econômica da Paraíba não era das melhores no cenário mais amplo. Entretanto, não se apresentava tão desesperadora como defende a historiografia vinculada ao IHGP. Isso porque a capitania/província viveu momentos de instabilidades e oscilações na produção, exportação e importação. Apesar disso, conseguiu manter um quadro positivo na maior parte desse período. O quadro econômico é fundamental para possibilitarmos a análise de como a Paraíba se inseria no mundo atlântico, pois a produção de açúcar e algodão e a pecuária demandavam mão de obra que era atendida também pela importação de africanos.

\section{O comércio de africanos na Paraíba do Norte}

O século XIX foi crucial para o comércio atlântico de escravizados. Após muitos conflitos internos, em 1807, a Inglaterra retirou-se dessa atividade. Por ser a maior potência econômica do mundo à época, essa saída representou grande impacto nas relações internacionais. Portugal e Brasil foram os mais afetados com isso.

A primeira investida diplomática inglesa sobre o comércio de africanos para o Brasil se deu no contexto da transferência da Corte portuguesa para o Rio de Janeiro. Em 1810, a Coroa lusa comprometeu-se com a Inglaterra em suspender a importação de africanos para o Reino. Alguns anos depois, o Rei D. João VI assinou, no Congresso de Viena, Declaração sobre o tráfico negreiro que tinha como finalidade acabar com o comércio ao Norte do Atlântico. Em 1817, novo acordo foi estabelecido por ambas as nações, reforçando as medidas anteriores. Porém, os interesses lusos estavam no Atlântico sul. Por mais que a Inglaterra pressionasse Portugal para suspender a atividade, deveria focar em outro ponto: as relações diretas entre África e Brasil. 
O momento mais crítico das relações diplomáticas que visavam o fim dessa prática se intensificou no período posterior à Independência. Após setembro de 1822, D. Pedro I mobilizou esforços para buscar o reconhecimento internacional da autonomia política do Brasil. Nesse sentido, as potências assumiam um papel estratégico. Após o reconhecimento feito por estas, o Brasil teria mais facilidade em conseguir uma melhor inserção internacional. A Inglaterra tinha grandes interesses no reconhecimento do Brasil. O maior deles estava no fim do comércio de escravos, além da abertura do mercado brasileiro. Assim, as pressões sobre o Brasil se tornaram cada vez maiores.

A Inglaterra não poderia se antecipar nesse processo. Como era aliada da Coroa portuguesa não seria interessante do ponto de vista diplomático reconhecer o Brasil antes que sua ex-Metrópole. Dessa maneira, Brasil, Portugal e Inglaterra participaram de várias rodadas de negociações a fim de sair com um tratado de amizade entre os países (GUIZELLIN, 2013). Isso só foi possível em 1825 com Tratado de Amizade e Aliança com Portugal e 1826 com a Convenção para o fim do comércio de escravos com a África (1826), estabelecido com a GrãBretanha. Neste último, o Brasil se comprometia em extinguir o comércio atlântico de escravizados em três anos.

Logo, em 1830, o Brasil não deveria mais estar envolvido com o comércio de escravizados africanos, tornando-se esta atividade ilegal. Apesar de, efetivamente, não terem interferido nessa atividade, algumas ações visavam ter o controle sobre a situação. Em maio de 1831, o Palácio do Governo da Paraíba recebeu uma orientação da Corte que determinava que

\begin{abstract}
Em despeito da extinção do semelhante comércio [de escravos com a costa da África], manda a Regência Provisória em nome do Imperador que V[ossa] Ex[celênci]a faça expedir uma circular a todos os juízes de paz das freguesias dessa província, recomendando-lhes toda vigilância policial a dito respeito, o que em caso de serem introduzidos por contrabando alguns escravos [ilegível] no território de cada uma das ditas freguesias, procedam imediatamente ao respectivo corpo de delito, e constando por este, que tal ou tal escravo boçal foi introduzido aí por contrabando, façam dele sequestro [ilegível] com o mesmo corpo de delito ao juiz criminal do território para ele proceder nos termos do direito em ordem a lhe ser retribuída a sua liberdade e punidos os usurpadores dela segundo o artigo 179 do novo código (CORRESPONDÊNCIA da Regência ao Presidente da Paraíba de 21 de maio, AHWBD, 1831).
\end{abstract}

Mesmo com tais orientações, os números de importações de africanos permaneceram altos. A Inglaterra intensificava a pressão sobre o Brasil. Isso causou problemas políticos. Parte das elites políticas brasileiras via esse processo como uma imposição dos ingleses. $\mathrm{O}$ que estava em debate - defendiam - era a Soberania brasileira, que ainda estava em 
construção. A saída encontrada pelo Congresso foi aprovar uma lei com o mesmo conteúdo do tratado sobre o comércio atlântico de escravizados. A partir de 07 de novembro de 1831 qualquer comerciante flagrado importando africanos seria preso e estes últimos ficariam livres.

Porém, esta lei ficou famosa por ser "para inglês ver". Ou seja, uma lei sem efetividade que respondia apenas às pressões inglesas. Inicialmente, causou impacto no comércio. Logo, porém, os traficantes perceberam que haveria formas de burlar a legislação por intermédio de subornos e novas estratégias. Em 1853, foi produzido um importante documento (Relatório Alcoforado) que nos relata tais estratégias. Inicialmente, os traficantes continuaram na atividade, porém utilizando-se de navios envelhecidos, houve queda nos preços dos africanos e as negociações eram feitas a prazo. A não repressão do governo brasileiro fez com que os traficantes percebessem que poderiam permanecer no negócio.

Além de não haver uma repressão montada pelo governo, o Relatório demonstra o envolvimento profundo de autoridades brasileiras nas práticas ilegais do tráfico. Montou-se, com o tempo, um aparato envolvendo desde os juízes de paz (os primeiros que deveriam fiscalizar os desembarques) até Ministros e parlamentares (RELATÓRIO Alcoforado, AN, IJ6 525, 1853). Frente a essas condições, o número de importações voltou a crescer.

Nos anos 1840, a repressão aumentou. Não por parte do governo brasileiro, mas pela pressão dos ingleses. Ainda assim, os traficantes continuavam a burlar a repressão, quando se estabeleceu uma "verdadeira operação de guerra" para manter essa atividade (REIS; GOMES; CARVALHO, 2010, p. 115). Uso de bandeiras distintas nas embarcações, documentos falsificados, rotas alternativas etc.

O leitor não pode esquecer que muitos interesses estavam envolvidos. As guerras napoleônicas, o reaquecimento da economia atlântica com a expansão industrial e o declínio de São Domingos permitiram uma retomada da produção no Brasil. A partir de 1830, a produção cafeeira no país cresceu exponencialmente e tornou-se o maior produto de exportação. Assim, a demanda por escravizados aumentava e os lucros desse comércio cresciam ainda mais (MARQUESE;TOMICH, 2009).

Como podemos observar tais transformações na Paraíba? Para responder a essa questão, cabe uma pequena apresentação de como funcionava o comércio no final do século XVIII. Durante o referido século, a Paraíba vivenciou altos e baixos em suas relações com a África. Diante de uma situação de crise que acabou levando-a à anexação, a Paraíba pouco se articulou diretamente com os portos africanos, sendo essa relação - na maior parte dos casos - 
mediada por Recife. Entretanto, nas décadas de 1720 e 1730, conseguimos identificar um aumento das relações entre Paraíba-África. Acreditamos ter sido uma estratégia utilizada por comerciantes e proprietários da Capitania para fugir às dificuldades financeiras. Compravam escravizados na África e revendiam na Paraíba e, principalmente, para as Minas.

Com a anexação, a Paraíba sofreu forte impacto em suas relações com o mundo atlântico. O monopólio exercido pela Companhia de Comércio Pernambuco e Paraíba dificultou fortemente a entrada de africanos na Paraíba. A Companhia foi criada em 1759 com o intuito de monopolizar as relações comerciais das duas capitanias. Todos os africanos importados para a Paraíba no período de 1759 a 1783 (quando a Companhia foi extinta) foram negociadas por ela.

Pesquisas sobre a venda de africanos na Paraíba pela Companhia de Comércio ainda não foram desenvolvidas. As poucas informações que identificamos foram tiradas da historiografia. Para José Octávio Mello (2008, p. 83), “A Companhia também falhava no fornecimento de escravos". Ao que nos parece, não se esforçava na venda de escravizados para esta capitania, pois a demanda era baixa.

António Carreira apresenta uma quantidade de 345 africanos vendidos na Paraíba nos anos de monopólio da Companhia. Esse total representa 0,63\% de todos os escravos desembarcados em Pernambuco de acordo com os números totais demonstrados pelo autor (CARREIRA, 1980, p. 345). Admite que o número pode ser maior, devido à proximidade geográfica das duas capitanias, permitindo que muitos escravos entrasse sem serem registrados. Esses dados apresentados por Carreira são muito próximos ao que TSTD (Transatlantic Slave Trade Database) ${ }^{10}$ indica, que aponta a entrada de 353 africanos. Essa ação da Companhia de Comércio desorganizou as relações diretas entre Paraíba-África - que já eram poucas -, tornando a capitania ainda mais dependente de Pernambuco na importação de africanos.

Na entrada do Oitocentos, as relações da Paraíba com o comércio atlântico de escravizados se deram pontualmente. Havia, basicamente, duas rotas: uma direta entre os portos da Paraíba e do litoral africano; outra que passava pelo porto de Recife. Dessa maneira, para podermos compreender o comércio de africanos escravizados ocorrido na Paraíba, devemos lançar luz sobre algumas informações deste comércio em Pernambuco.

Esta província viveu um período de crescimento nas importações de africanos no século XIX, mesmo com a proibição em 1831. Em linhas gerais, Pernambuco recebeu por volta de 297.014 africanos escravizados, de acordo com o TSTD. Esse número representa 
$82,72 \%$ das importações do século anterior (que totalizou cerca de 359.052). Se lembrarmos que isso se deu em meio século, proporcionalmente o comércio de escravizados no Oitocentos foi muito mais intenso na referida província, como sugerem Silva e Eltis (2008, p. 112). Estes mesmo autores calculam ter sido o porto de Recife entre o quinto e sexto que mais recebeu escravos africanos.

Gráfico 2 - Importação de africanos escravizados para Pernambuco no Século XIX

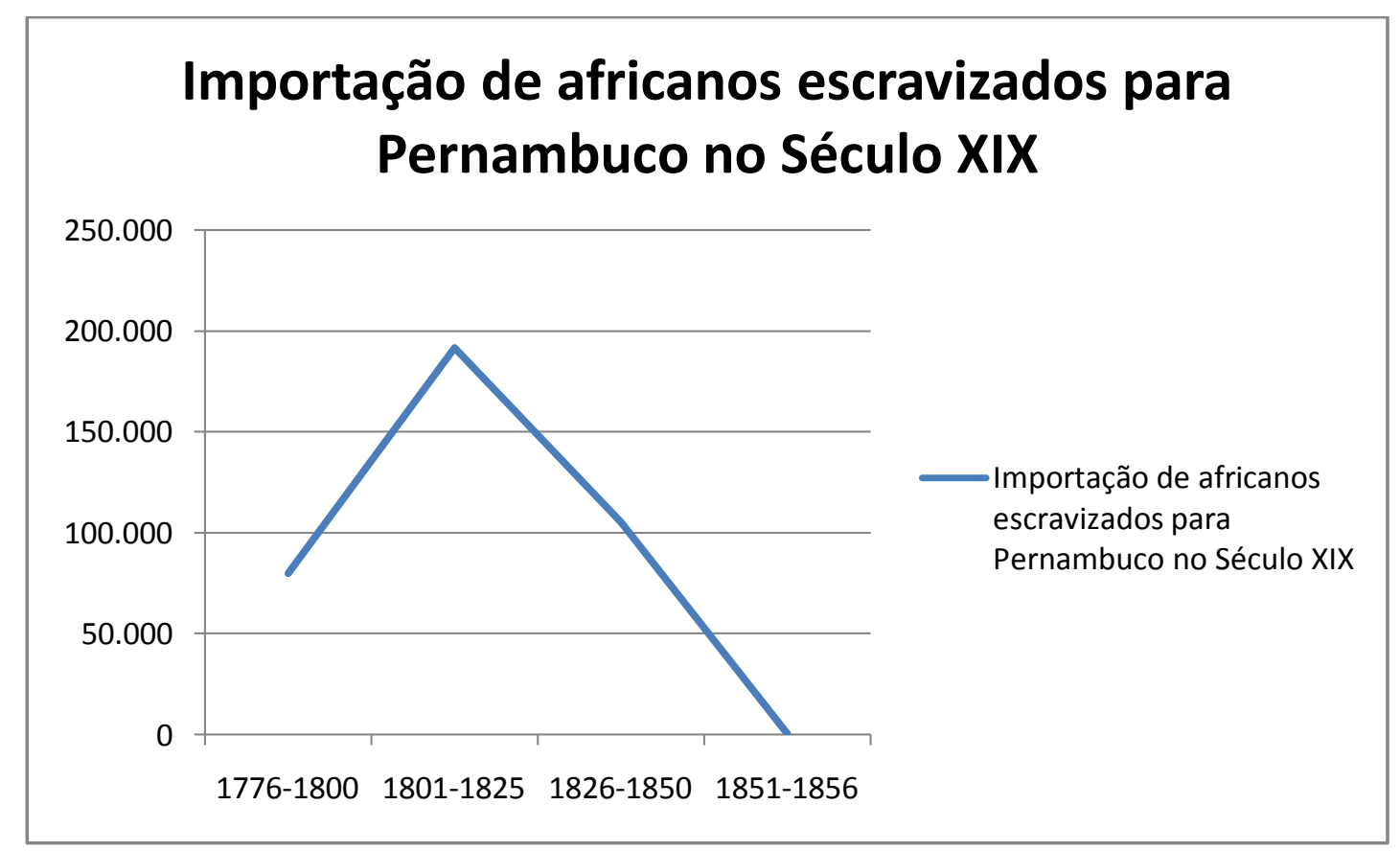

Fonte: http://www.slavevoyages.org/tast/assessment/estimates.faces. Acesso em 31 de out de 2014.

Não conseguimos fontes seriais que demonstrassem a entrada de africanos na Paraíba. Contudo, em vários documentos, identificamos essa relação direta entre a província e a África. Em 1820, temos o exemplo do Brigue Cabragante que desembarcou em terras da 
Paraíba com 46 africanos. Vindo da região sudeste da África, em especial de Quilimane, área que se tornou um porto fundamental para o tráfico de escravos no século XIX, a embarcação tinha como capitão Pedro Lagrão. (RELATÓRIO Ministério da Fazenda, CRL, 1821-23)

Dois anos depois, de acordo com o Relatório do Ministro da Fazenda Manoel Jacinto Nogueira da Gama, a província pagou um total de 1:122\$264 de subsídios por escravos novos. Como o imposto pago por cada escravo importado era de $9 \$ 000$, conseguimos totalizar a quantidade de 124 africanos desembarcados. No ano seguinte, José Inácio de Sousa chegava com a sumaca Desengano desembarcando 217 africanos, vindos de Malembo. Logo depois, ele seguiu viagem para a Bahia.

Em 1829, só identificamos o registro da entrada de um africano, tendo em vista que o dízimo de escravos novos foi de apenas $9 \$ 168$ de acordo com o apresentado pelo Ministro Felisberto Caldeira Brant Pontes. Em contrapartida, a saída de escravizados foi relativamente alta, registrando $844 \$ 324$ de meia-sisa para o referido ano. Em 1826, o número foi de 800\$000. Os dados demonstram uma saída progressiva de cativos da Paraíba para outras províncias, pois em 1823 o referido subsídio circulava em torno dos 349 mil réis e chegou a 541 milréis no ano posterior. Contudo, as informações dos relatórios do Ministério da Fazenda não nos permite saber se esses escravizados eram todos africanos (RELATÓRIO Ministério da Fazenda, CRL, 1829).

Não podemos esquecer que essas são as poucas evidências que conseguimos ter acesso. A quantidade de africanos que entraram e saíram da Paraíba foi maior do que identificamos. O contrabando sempre foi uma marca constante desse comércio. Além do contrabando, que dificulta identificar ao certo quantos africanos chegaram diretamente à Paraíba, parte dos escravizados que desembarcavam nos portos desta província não eram taxados na mesma, sendo esse trabalho feito em Pernambuco.

Fizemos uma pesquisa dos registros de entrada e saída de embarcações no porto de Recife publicados no Diário de Pernambuco entre 1825 e 1831 e não conseguimos constatar nenhuma embarcação que levasse escravizados com destino à Paraíba. Se identificamos duas formas de entrada de africanos na Paraíba e esta se relacionava poucas vezes com os portos africanos, a hipótese que nos resta é que a rota seria feita por terra e não por mar. Essa era, aliás, uma prática comum: a formação de caravanas com africanos importados ilegalmente para serem vendidos em várias províncias, como veremos adiante.

Há também outras formas de importação de africanos. Aqueles que já viviam no Brasil e foram vendidos para a Paraíba. Em março de 1830, o Diário de Pernambuco anunciava a 
venda de uma escrava de nação Angola apta para todos os serviços. O único requisito era que fosse para fora da província. Os interessados deveriam procurar o responsável pela venda na rua do Mundo Novo na capital pernambucana (DIÁRIO DE PERNAMBUCO de 20 de março, UFDC, 1830, p. 1376). Esse caso não foi isolado e era comum o anúncio com o requisito de venda para outra província.

Além dessa prática de anunciar a venda para fora da província, ocorriam casos de compra de escravizados africanos para serem vendidos em outras regiões fora de Pernambuco. Em 29 de janeiro de 1830, havia um anúncio de compra de "Uma negra de nação, sendo mossa e boa figura", sem vício ou doença que sabia cozinhar e engomar ou fazer qualquer outro tipo de trabalho doméstico. Ela seria comprada para fora de Pernambuco (DIÁRIO DE PERNAMBUCO, 29 de janeiro, UFDC, 1830, p. 1215). Esses casos de venda e compra de africanos para fora da província leva-nos a pensar como parte dos africanos teria sido importada para Paraíba, por intermédio da praça de Recife. As negociações entre províncias continuaram, mesmo assumindo novas características.

Após a lei de 1831, apesar da persistência do tráfico, a atividade teve que passar por mudanças para poder burlar a lei. Além daquelas que já foram citadas, como utilizar outras embarcações, era comum que os africanos fossem desembarcados à noite e passassem alguns dias para serem vendidos. Nesse período de ilegalidade, Mahommah Baquaqua foi preso e vendido em Pernambuco. Após vários anos, ele conseguiu a liberdade nos Estados Unidos, alfabetizou-se e deixou seu relato de como funcionava o mercado ilícito de escravos.

\begin{abstract}
Quando um navio negreiro aporta, a notícia espalha-se como um rastilho de pólvora. Acorrem, então, todos os interessados na chegada da embarcação com sua carga de mercadoria viva, selecionando do estoque aqueles mais adequados aos seus propósitos, e comprando os escravos da mesmíssima maneira como se compra gado ou cavalos num mercado. Mas, se num carregamento não houver o tipo de escravo adequado às necessidades e desejos dos compradores, encomenda-se ao Capitão, especificando os tipos exigidos, que serão trazidos na próxima vez em que o navio vier ao porto. Há uma grande quantidade de pessoas que fazem um verdadeiro negócio dessa compra e venda de carne humana e que só fazem isso para se manter, dependendo inteiramente desse tipo de tráfico (BAQUAQUA, 1988, p. 273-274).
\end{abstract}

Essa rede comercial envolvia várias pessoas e um recorte geográfico considerado. A proximidade econômica e geográfica da Paraíba com Pernambuco nos faz levar a acreditar que em um desses desembarques, alguns dos africanos - incluindo possíveis parceiros de Baquaqua - tenham sido vendidos na Paraíba. Após serem vendidas, essas pessoas eram 
enviadas aos seus donos que, em alguns casos, ficavam em outras províncias. Nesse caso, montavam-se caravanas com o objetivo de transportar os escravizados.

Em carta escrita ao Diário de Pernambuco, em 17 de abril de 1837, um leitor anônimo (que assinava como $O$ Anjo Gabriel) reclamava da decisão de tornar ilegal a importação de africanos novos. E nesta carta relatava:

\begin{abstract}
Um destes dias, e não faz muito tempo estando deitado de papo para sima em minha typoia meditando sobre isto mesmo [o fim do tráfico] vi passar, (porque a minha casa fica na beira da estrada de minha moradia), bastante gente armada cujo número representava mais de quarenta homens, e no meio destes alguns 200 colonos Africanos, - pois assim apilidou um dos taes conductores: dice-me outro que haviao desembarcado para as partes do engenho Boto (?); e que tinhão vindo por conta, ou pertencião a hum homem tão manso, e pacifico, que assimilhava-se a hum cordeiro; dice mais que outra Embarcação havia desovado em outra praia; mas que muitas pessoas recavão (?) comprar os collonos de aquela Embarcação por já terem morrido secenta e tantos, tal vez por virem muitos apinhados [...] (DIÁRIO DE PERNAMBUCO, 17 de abril, UFDC, 1837).
\end{abstract}

Apesar de todas as estratégias e sucesso na continuidade do comércio ilegal de pessoas escravizadas, havia recomendações oficiais para a repressão. No caso da Paraíba, em 1848, o então Presidente João Antônio de Vasconcelos, avisava ao Ministro da Justiça que a província não tinha vivenciado nada a esse respeito. Apesar disso, deixava o Chefe de Polícia e autoridades policiais do litoral vigilantes, caso qualquer tentativa de desembarque ilegal fosse feita (CORRESPONDÊNCIA do Presidente da Paraíba ao Ministro da Justiça n.39 de 19 de julho, AN, IJ1 301, 1848). Em seu período de governo talvez ele não tenha presenciado nenhum caso ou estava tentando ocultar tais experiências, pois a Paraíba já havia vivido casos de desembarques ilegais.

Com a ilegalidade, houve mudanças na estrutura de desembarques. Os portos grandes não eram mais aptos para receber embarcações ilegais. Essa escolha se dava não apenas pelas condições naturais que favorecessem o desembarque, bem como das relações políticas que envolviam os proprietários das terras e os traficantes. Os navios não chegavam em terra firme. Pequenos barcos e jangadas iam até eles e desembarcavam os africanos escravizados, sendo esta, inclusive, uma atividade que movimentou parte da economia local ao empregar a população livre pobre que habitava tais praias (CARVALHO, 2009; CARVALHO, 2012, p. 226-227; 239-240). Vale ressaltar que boa parte dos desembarques ilegais teve apoio população local, muitos livres e pobres como barqueiros e jangadeiros (RODRIGUES, 2000, p. 175). 
Exatamente assim que alguns desembarques ilegais ocorreram na Paraíba após 1831 e que conseguimos identificar. Um deles ocorreu em Lucena, em abril de 1842. Ao desembarcarem, foram presos três africanos boçais entregues às providências do palácio do governo (CORRESPÔNDECIA do sub prefeito de Lucena ao Presidente da Província de 2 e 9 de abril, AHWD, cx 20, 1842). A quantidade pequena de escravizados pode apontar para uma segunda etapa da viagem em que os africanos já haviam chegado ao Brasil e estavam sendo transferidos à Paraíba. Esta praia possuía poucos habitantes e estes viviam quase que exclusivamente da pesca e cabotagem. Dessa maneira, poderiam ser - como já afirmamos envolvidos com o tráfico ilícito até como uma forma de manutenção econômica de suas vidas.

Em 1845, outra praia foi escolhida para o desembarque ilegal: Pitimbu. A polícia tentou impedir a ação, apreendendo a carga e a embarcação. Entretanto, a ação repressiva não obteve êxito. Quarenta e dois dos africanos desembarcados foram levados à cidade da Parahyba do Norte (CARVALHO, 2009, p. 163). Pitimbu fica na divisa entre Pernambuco e Paraíba e, provavelmente, os traficantes tinham por objetivo atender demandas das duas províncias. Nas proximidades do rio Abiaí, próximo a Pitimbu, houve um desembarque bem sucedido, em 1836, contando com o auxílio do Juiz de Paz do local (MEDEIROS, 1999, p. $53)$.

\section{Considerações finais}

A capitania/província da Paraíba não constou entre as maiores importadoras de africanos do Brasil. Entretanto, assim como várias outras, possuía escravizados vindos da África. Dessa maneira, como essas pessoas eram trazidas para essa capitania/província? Para compreendermos essa questão, fizemos um percurso pela economia da Paraíba na primeira metade do século XIX.

Apesar de a historiografia do IHGP indicar um momento de profunda calamidade, percebemos que a situação não era essa. Mesmo não demonstrando grande enriquecimento econômico, a Paraíba manteve um quadro de saldos positivos em quase toda a primeira metade do Oitocentos. Devido ao processo de reorganização econômica e do quadro mais amplo do Brasil e do Atlântico, houve muitas oscilações nos números de exportação e nas produções de açúcar, algodão e gado - principais atividades da capitania/província. 
Entretanto, o cenário não era de crise profunda e a Paraíba manteve-se em uma situação superavitária por muitos anos.

Essa situação fazia com que os proprietários da capitania/província necessitassem de mão de obra. Muitos eram os trabalhadores livres pobres e os escravizados nascidos no Brasil que trabalhavam nesses processos produtivos. Contudo, os africanos estiveram presentes. $\mathrm{O}$ comércio atlântico de escravizados na primeira metade do século XIX deve ser pensado com o recorte de antes de 1831 e depois desta data, devido à ilegalidade decretada no referido ano. Até 1831, as importações da Paraíba se davam ou diretamente com a África ou por intermédio do porto de Recife. Com as novas rotas estabelecidas após a lei de 7 de novembro, foram utilizadas praias mais desertas e na divisa com Pernambuco, favorecendo as elites de ambas as províncias. Assim, tanto Lucena como Pitimbu tiveram casos registrados de desembarques ilegais. Mesmo com as mudanças, devemos destacar que, em toda a primeira metade do século XIX, esse comércio da Paraíba se dava de maneira pontual, sobretudo, se pensarmos em comparação com outros grandes centros econômicos.

\footnotetext{
${ }^{1}$ Vale ressaltar que não havia unidade entre as elites da Paraíba sobre a subordinação a Pernambuco. Alguns setores, como os produtores de Mamanguape, eram a favor da anexação, que se apresentava muito mais vantajosa para esse grupo. A resistência à subordinação vinha mais de setores vinculados às elites da Capital. Cf. Chaves Júnior (2013).

${ }^{2}$ Até o ano de 1930, a capital e a capitania/província possuíam os mesmo nomes, sendo grafados como "Parahyba". Para evitarmos confusão, utilizaremos o termo "Paraíba" quando nos referirmos à capitania/província e "Parahyba" quando estivermos tratando da cidade.

${ }^{3}$ Em uma análise historiográfica sobre o período da anexação, José Inaldo Júnior (2013) demonstra como a historiografia do IHGP esteve marcada por uma oposição ao "imperialismo pernambucano", expresso, sobretudo, na anexação. Para justificar a tese de que a economia da Paraíba sofreu negativamente nesse período, os historiadores desse Instituto apresentam interpretações de que o início do século XIX (período imediatamente posterior ao fim da anexação) foi terrível. Ver também sobre isso em Paiva (2009).

${ }^{4}$ Os números apresentados na documentação estão em quintal. De acordo com Russel-Wood (1981, p. 305), um quintal equivale a quatro arrobas. Fizemos a adaptação para facilitar o cálculo. Os números em quintais são para os referidos anos respectivamente: $9.344 ; 6.894 ; 7.707 ; 3.677 ; 2.380 ; 2.313 ; 3.641$.

${ }^{5}$ Sobre o movimento de 1817 e o caráter econômico e político dessas elites, ver Mariano (2013)

${ }^{6}$ AHU_CU_014, Cx. 34, D. 2473, 1798; AHU_CU_014, Cx. 34, D. 2490, 1799; AHU_CU_014, Cx. 36, D. 2575, 1800; AHU_CU_014, Cx. 37, D. 2673, 1801; AHU_CU_014, Cx. 39, D. 2744, 1802; AHU_CU_014, Cx. 40, D. 2807, 1803; AHU_CU_014, Cx. 42, D. 2989, 1804; AHU_CU_014, Cx. 45, D. 3200, 1805; AHU_CU_014, Cx. 47, D. 3314, 1806.

${ }^{7}$ Os números das importações e exportações foram apresentados na documentação em cruzados. Como os outros dados estão sendo mostrados em réis, utilizamos a adaptação feita por Paiva $(2009$, p. 36) de cruzados para réis.

${ }^{8}$ Em 1825, o Brasil assina um Tratado de Amizade e Aliança com Portugal que previa o pagamento de 2 milhões de libras esterlinas para o reconhecimento da Independência do Brasil. Cf. <daí-mre.serpro.gov.br/atosinternacionais/bilaterais/1825>.

${ }^{9}$ Cf. Livros de Batismos I, II e III, Arquivo Eclesiástico da Paraíba, e Livro de Notas da Cidade da Parahyba (1841-1846), Arquivo do IHGP.

${ }^{10} \mathrm{Cf}$. <www.slavevoyages.org >
} 


\section{Fontes}

Impressas

BAQUAQUA, Mahommah. Biografia de Mahommah Baquaqua. Apresentação de Silvia Lara. Revista Brasileira de História. Vol. 8, n. 16, 1988, p. 269-284.

PINTO, Irineu. Datas e notas para a história da Paraíba. João Pessoa: Universitária/UFPB, 1977. 2 Vols.

Internet

\section{University of Florida Digital Collections (UFDC)}

Diário de Pernambuco

Foram pesquisados os jornais de novembro de 1825 a dezembro de 1830.

Disponíveis em: http://ufdc.ufl.edu/AA00011611. Acesso em: 15 janeiro 2015.

\section{Center for Research Libraries (CRL)}

Relatórios de Presidente de Província da Paraíba

Disponível em: <http://www.crl.edu/brazil/provincial/para\%C3\%ADba>. Acesso em:

Foram pesquisados os relatórios anuais entre 1837 e 1852.

\section{Relatórios do Ministério da Fazenda}

Disponíveis em: http://www.crl.edu/brazil/ministerial/fazenda. Acesso em:

Foram pesquisados os relatórios dos anos de 1821-23 a 1829.

\section{Transatlantic Slave Trade Database (TSTD)}

Disponível em: http://www.slavevoyages.org/tast/index.faces.

\section{Manuscritas}

\section{Arquivo Eclesiástico da Paraíba (AEPB)}

Livros de batismos da Freguesia Nossa Senhora das Neves, 1833-60.

I - 1833-1841

II $-1846-1850$

III $-1850-1857$

IV $-1857-1863$

\section{Arquivo Histórico Ultramarino (A.H.U.)}


AHU_CU_014, Cx. 34, D. 2471, 1798.

AHU_CU_014, Cx. 34, D. 2473, 1799.

AHU_CU_014, Cx. 34, D. 2490, 1799.

AHU_CU_014, Cx. 36, D. 2575, 1800.

AHU_CU_014, Cx. 37, D. 2673, 1801.

AHU_CU_014, Cx. 39, D. 2744, 1802.

AHU_CU_014, Cx. 40, D. 2807, 1803.

AHU_CU_014, Cx. 42, D. 2989, 1804.

AHU_CU_014, Cx. 45, D. 3200, 1805.

AHU_CU_014, Cx. 47, D. 3314, 1806.

\section{Arquivo Histórico Waldemar Bispo Duarte (AHWBD)}

Caixa 010, 1830-1833.

- CORRESPONDÊNCIA da Regência ao Presidente da Paraíba de 21 de maio de 1831.

Caixa 020, 1842.

- CORRESPONDÊNCIA do Sub-Prefeito de Lucena ao Presidente da Paraíba em 2 e 9 de abril de 1842 .

\section{Arquivo do Instituto Histórico e Geográfico Paraibano (AIHGP)}

Livro de Notas da cidade da Parahyba do Norte (1841-1846).

Arquivo Nacional (AN)

CORRESPONDÊNCIA do Presidente da Paraíba ao Ministro da Justiça n.39 de 19 de julho, AN, IJ1 301, 1848

RELATÓRIO Alcoforado, AN, IJ6 5251853.

\section{Referências Bibliográficas}

ALMEIDA, Horácio de. História da Paraíba. João Pessoa: Editora Universitária/UFPB, 1978. 2 volumes. [ $1^{a}$ edição do volume 1 de 1966].

CARREIRA, Antônio. As Companhias Pombalinas: de Grão-Pará e Maranhão e Pernambuco e Paraíba. Lisboa: Editorial Presença, 1980.

CARVALHO, Marcus J. M. de. A repressão tráfico atlântico de escravos e a disputa partidária nas províncias: os ataques aos desembarques em Pernambuco durante o governo praieiro, 1845-1848. Tempo. Revista do Departamento de História da UFF, v. 27, 2009, p. $151-167$.

O desembarque nas praias: o funcionamento do tráfico de escravos depois de 1831. Revista de Historia (USP), v. 167, 2012, p. 223-260.

CERVO, Amado Luiz; BUENO, Clodoaldo. História da Política Exterior do Brasil. 3 ed. Brasília: Editora Universidade de Brasília, 2008.

CHAVES JÚNIOR, Inaldo. "As duras cadeias de hum governo subordinado": história, elites e governabilidade na Capitania da Paraíba (c.1755-1799). Dissertação de Mestrado em História. Instituto de Ciências Humanas e Filosofia - UFF, 2013.

GUIZELIN, Gilberto da Silva. Comércio de almas e política externa: a diretriz atlânticoafricana da diplomacia imperial brasileira (1822-1856). Londrina: Eduel, 2013 
LUNA, Francisco Vidal; KLEIN, Herbert S. Escravismo no Brasil. São Paulo: Edusp: Imprensa Oficial do Estado de São Paulo, 2010.

MARIANO, Serioja. Gente opulenta e de boa linhagem: família, política e relações de poder na Paraíba (1817-1824). João Pessoa: Editora da UFPB, 2013

MARIZ, Celso. Evolução econômica da Paraíba. 2 ed. João Pessoa: A União, 1978.

MARQUESE, Rafael; TOMICH, Dale. O Vale do Paraíba escravista e a formação do mercado mundial do café no século XIX. In.: GRINBERG, Keila; SALLES, Ricardo (orgs). O Brasil Imperial: 1831-1870. Rio de Janeiro: Civilização Brasileira, 2009, p. 339-386. Volume 2.

MEDEIROS, Maria do Céu. O trabalho na Paraíba Escravista. In.: ; SÁ, Ariane Norma de Menezes. O trabalho na Paraíba: das origens à transição para o trabalho livre. Editora Universitária/Ufpb, 1999, p. 17-99.

MELLO, José Octávio de Arruda. História da Paraíba: lutas e resistências. 11 ed. João Pessoa: A União, 2008.

NASCIMENTO FILHO, Carmelo. Fronteira Móvel: os homens livres pobres e a produção do espaço da Mata Sul da Paraíba (1799-1801). Dissertação (Mestrado em Geografia). Centro de Ciências Exatas e da Natureza. Universidade Federal da Paraíba. 2006.

PAIVA, Yamê Galdino de. Capitania da Paraíba: população e circuitos mercantis na virada para o século XIX. Monografia (Licenciatura em História). Centro de Ciências Humanas Letras e Artes. Universidade Federal da Paraíba. 2009.

PRADO JÚNIOR, Caio. História econômica do Brasil. São Paulo: Brasiliense, 2006.

REIS, João José; GOMES, Flávio dos Santos; CARVALHO, Marcus J. M. de. O Alufá Rufino: tráfico, escravidão e liberdade no Atlântico negro (c.1822 - c. 1853). São Paulo: Companhia das Letras, 2010.

RODRIGUES, Jaime. O Infame Comércio: propostas e experiências no final do tráfico de africanos para o Brasil (1800-1850). Campinas, SP: Editora da Unicamp, 2000.

RUSSEL-WOOD, A J. R. Fidalgos e Filantropos. A Santa Casa de Misericórdia da Bahia, 1550 - 1755. Tradução de Sérgio Duarte. Brasília: Editora Universidade de Brasília, 1981. 